\title{
IMPORTÂNCIA DA AVALIAÇÃO DA APRENDIZAGEM NO ENSINO A DISTÂNCIA E OS INSTRUMENTOS DE AVALIAÇÃO UTILIZADOS NA ÁREA DA SAÚDE
}

\author{
Fabiola de Azevedo Mello, Maria Eliza Nigro Jorge \\ Universidade do Oeste Paulista - UNOESTE, Pós-Graduação em Avaliação do Ensino e da Aprendizagem Presidente \\ Prudente, SP. E-mail: fabiola-azevedo@hotmail.com.
}

\section{RESUMO}

O objetivo desse trabalho foi demonstrar a importância da avaliação da aprendizagem no ensino a distância e os instrumentos de avaliação utilizados na área da saúde. O portfólio é um instrumento que apresenta um conjunto de todos os trabalhos confeccionados pelos alunos durante a disciplina ou curso, auxiliando o estudante a avaliar seu próprio trabalho. O fórum de discussão é utilizado para compartilhar experiências e perspectivas entre os alunos e docentes, com o intuito de aprofundar as discussões e reflexões a respeito do conteúdo. O seminário virtual apresenta o assunto através do uso de diferentes maneiras de construção coletiva online, enquanto o mapa conceitual avalia a aprendizagem real do aluno através de uma estrutura conceitual ilustrativa. Desta maneira, o uso dos diferentes instrumentos de avaliação contribuem no processo de ensino e aprendizagem, sendo a EAD uma tendência na área da saúde, fortalecendo e transformando as práticas dos profissionais dessa área.

Palavras-chave: Ensino a distância na área da saúde, portfólio, fórum de discussão, seminário virtual e mapa conceitual.

\section{IMPORTANCE OF LEARNING ASSESSMENT IN DISTANCE LEARNING AND EVALUATION USED INSTRUMENTS IN THE HEALTH AREA}

\begin{abstract}
The aim of this study was to demonstrate the importance of assessing learning in distance learning and assessment tools used in healthcare. The portfolio is a tool that presents a set of all the works made by students during the course or course, helping students to evaluate their own work. The discussion forum is used to share experiences and perspectives among students and teachers, in order to deepen the discussions and reflections on the content. The virtual seminar introduced the subject by using different ways of online collective construction, while the conceptual map evaluates the student learning through an illustrative conceptual framework. Thus, the use of different assessment tools help in the process of teaching and learning, and distance education a trend in health care, strengthening and transforming the practices of professionals in this area.

Keywords: Distance learning in health, portfolio, forum, virtual seminar and conceptual map.
\end{abstract}




\section{INTRODUÇÃO}

Nos últimos anos, o cotidiano do ser humano vem sofrendo alterações em seus hábitos, condutas e crenças. Estamos na Era Digital, marcada pelo desenvolvimento rápido e por inúmeros acontecimentos. São notórias as mudanças sofridas nos diversos setores da sociedade impulsionadas pelo desenvolvimento tecnológico (PINTO, 2012).

A inovação da tecnologia abrange muito mais do que algumas mudanças, envolve conexões e interações (LORENZETTI, 2012). Esse tipo de avanço ocorre de maneira desenfreada, onde os indivíduos procuram constantemente por novidades em termos tecnológicos e a educação brasileira, consequentemente, vem sendo transformada de maneira significativa.

Uma das categorias de ensino que aprensentam significativo crescimento no mundo é a Educação a Distância (EAD), cuja finalidade é educar. $O$ uso de novas tecnologias facilita a diversificação e ampliação de diferentes programas, que permitem a interação quase presencial entre educadores e alunos (SARAIVA, 1996).

O presente trabalho se divide em três partes: na primeira, busco esclarecer as diferenças existentes entre a educação presencial, semipresencial e a distância; na segunda, defino os conceitos de avaliação a distância e mediação pedagógica, e na terceira parte mostro os instrumentos de avaliação utilizados na área da saúde.

O objetivo desse estudo foi demonstrar a importância da avaliação da aprendizagem no ensino a distância e os instrumentos de avaliação utilizados na área da saúde.

\section{DESENVOLVIMENTO}

\section{ESCLARECENDO CONCEITOS}

Hoje tem-se a educação presencial, semipresencial (parte presencial/parte a distância) e educação a distância (também chamada de virtual). A presencial caracteriza-se pelo encontro de educadores e alunos em um determinado local conhecido como sala de aula, sendo esta a modalidade de ensino mais comum em nosso país. Na educação semipresencial, parte das aulas ocorrem a distância através do uso de tecnologias, e a outra parte em um polo presencial. Já na educação a distância, podem ou não existirem momentos presenciais, mas ocorrem com educadores e alunos separados fisicamente e unidos através do uso de tecnologias de comunicação.

A educação a distância fez-se necessária devido as exigências do mercado e da globalização, sendo uma maneira de aprendizagem mais rápida devido ao uso das tecnologias digitais em ambientes distantes. Atualmente, o ser humano necessita de rápidas informações e capacitação constante para que possa competir no mercado mundial (RODRIGUES, 2013).

De acordo com o Decreto 5.622, de 19 de dezembro de 2005, a EAD é uma modalidade que faz uso de tecnologias para o processo de ensino e aprendizagem, apresentando metodologia, gestão e avaliação diferenciadas. A avaliação dos estudantes, defesas de trabalhos de conclusão de curso, estágios obrigatórios e atividades relacionadas ao laboratórios de ensino também são obrigatórios nesse tipo de modalidade. Sendo este um processo de avaliação que deve ser muito bem planejado, pois exige que sejam previstas todas as ações realizadas no ambiente virtual.

\section{AVALIAÇÃO DA APRENDIZAGEM NA EDUCAÇÃO A DISTÂNCIA (EAD)}

A palavra avaliação deriva-se de "valer", que é proveniente do latim vãlêre e refere-se a ter valor, ou seja, é a valoração de algo. Avaliar é uma atividade essencial e que não dissocia-se de qualquer ação que tem o intuito de provocar mudanças, é um processo contínuo onde o aluno deve ser observado e avaliado ao longo de todo o curso e não através de provas e testes. A ação educativa é uma atividade constante da avaliação, tanto na avaliação da aprendizagem, do ensino e da avaliação do projeto educativo (DARSIE, 2013). 
A avaliação da aprendizagem tem como objetivo executar uma complexidade maior de diferentes competências cognitivas, sendo possível transformar o aluno em um autodidata, capaz de desenvolver seu próprio pensamento em busca de diferentes caminhos e o direcionamento para o estudo a distância.

Segundo Piletti (1987) a avaliação é um processo contínuo que busca interpretar os diferentes conhecimentos, atitudes e habilidades do educando, com o intuito de observar mudanças comportamentais propostas nos objetivos educacionais.

$\mathrm{Na}$ atualidade, o docente não representa um repassador ou transmissor de conteúdos, mas sim um mediador, colocando-se como facilitador, incentivando e motivando a aprendizagem. A mediação pedagógica acaba sendo uma atitude, como uma ponte entre a aprendizagem e o aprendiz, com ênfase no diálogo, na troca de experiências e no debate.

Na educação a distância, a mediação assume papel de extrema importância, já que a distância física entre os indivíduos exige recursos, habilidades, estratégias e competências diferentes do modelo de educação convencional. Com a inserção de tecnologias e a EAD, a função mediadora do professor adquiriu forte e rápido impulso devido as exigências dessa nova maneira de ensinar.

O processo de avaliação na educação a distância é composto por Ambientes Virtuais de Aprendizagem (AVA), que funcionam como salas de aula, completamente diferente dos cursos presenciais, onde existem paredes, cadeiras e quadros.

A função diagnóstica é um tipo de modalidade da avaliação que analisa conteúdos com a finalidade de identificar as dificuldades do aluno, sendo uma observação prévia do nível de conhecimento do aluno no início do curso.

Outro tipo de função é a formativa, que é realizada durante todo o processo de ensino e de aprendizagem, cujo intuito é verificar se o aluno aprendeu o que havia sido proposto durante todo o planejamento do educador.

A avaliação da aprendizagem na EAD requer um corte com o modelo tradicional. Esse tipo de modalidade de ensino ainda sofre preconceitos, já que a sociedade só dá credibilidade ao processo tradicional de avaliação. Deve-se entender que este é um processo novo e que apresenta inúmeras ferramentas tecnológicas que não podem ser comparadas ao modelo tradicional.

\section{INSTRUMENTOS DE AVALIAÇÃO PORTFÓLIO}

O portfólio é um instrumento onde se encontram um conjunto de todos os trabalhos confeccionados pelos alunos durante a disciplina ou o curso, além de contar suas dificuldades e avanços. Seu principal objetivo é auxiliar o estudante a avaliar seu próprio trabalho (VILLAS BOAS, 2016). É conhecido por fazer revelações, já que os incentiva a cuidarem de sua aprendizagem.

A escolha do instrumento de avaliação e de seu desenvolvimento adequado são essenciais para a obtenção de dados confiáveis, sendo possível garantir o objetivo da avaliação proposta, a construção da síntese e as transformações, sendo o portfólio um desses instrumentos.

Ele costuma ser relacionado com a avaliação formativa, pois é elaborado pelo próprio aluno, com a presença ou não de algum parceiro(s). Segundo Villas Boas (2004), o portfólio vincula-se a avaliação e ao trabalho pedagógico.

\section{O PORTFÓLIO NA ÁREA DA SAÚDE}

Esta ferramenta está presente na área médica em âmbitos diferentes de formação como a graduação e residência. Este intrumento acaba sendo aproveitado como registro, planejamento, avaliação, memória e autoavaliação. Todos o educadores dessa área que fazem uso desse instrumento devem refletir de maneira crítica sobre o processo saúde-doença e transformar assim, suas práticas de saúde, com o intuito de possibilitar a compreensão de uma racionalidade 
que seja crítico-reflexiva no aumento do conceito de saúde, voltadas para a atenção integral a saúde humana.

Desta forma, o portfólio é uma ferramenta que possibilita tanto a avaliação quanto a formação do aluno, sendo este capaz de construir sua aprendizagem, selecionando de maneira direta suas informações, apresentando as experiências mais relevantes e representativas.

\section{FÓRUNS DE DISCUSSÃO}

O fórum de discussão é um instrumento interativo utilizado com frequencia nos modelos de EAD que prezam a construção e comunidades de aprendizagem online. Para que a comunidade seja construída, o fórum não pode ser um espaço onde existam troca de informações assíncronas ou para que as mensagens sirvam somente como avaliação. Deve existir um contexto entre os diálogos, com o compartilhamento de experiências e perspectivas entre os alunos e docentes, cujo o intuito é aprofundar as discussões e reflexões a respeito do conteúdo (DE MORAIS BICALHO, 2012).

Para os profissionais da área da saúde essa ferramenta propicia a troca de experiências vivenciadas durante o dia-a-dia por cada aluno em seu local de trabalho, favorecendo o diálogo e a troca de diferentes conhecimentos entre eles.

Quando um integrante do fórum posta uma mensagem, parte-se do princípio de que as informações ali contidas são claras e que todos podem compreender. Esse é o princípio chamado de mútua compreensão, onde cada aluno pode refazer suas informações e manter ativo o fluxo de comunicação. Deve-se destacar que nesse ambiente nem todos os alunos encontram-se em igualdade de conhecimento. Por isso, a mediação pedagógica exercida pelo professor-tutor é fundamental para que haja o entendimento e compreensão do conteúdo por todos os alunos, provocando avanços na aprendizagem.

\section{MAPA CONCEITUAL}

O mapeamento conceitual (MP) é utilizado para ilustrar uma estrutura de conceitos, ou seja, apresentam uma organização em forma de hierarquia, que incluem setas, sendo diagramas de significados. Deve-se tomar cuidado para não serem confundidos com organogramas ou fluxogramas, já que não apresentam temporalidade ou poder (BUCHWEITZ, 2013)

Esse tipo de instrumento deve apresentar os conceitos mais importantes e relevantes de um determinado conteúdo. As setas podem dar o sentido de direção e determinar a relação entre todos os conceitos específicos, mas seu uso não é obrigatório. Nesse tipo de modelo, os conceitos específicos ficam no topo da hierarquia e os menos abrangentes, em sua base.

Podem ser usados como instrumento de ensino e/ou avaliação da aprendizagem, além de auxiliar na análise de um curriculo. Durante a avaliação, o mapa é utilizado com o intuito de verificar se o aluno realmente sabe o conceito dos temas, como ele é capaz de estruturá-lo, relacioná-lo e externalizá-lo (MOREIRA, 2013). Desta forma, para que ele seja utilizado, o docente precisa aplicar esse recurso durante suas aulas para que os estudantes possam produzi-los com sucesso.

\section{SEMINÁRIO VIRTUAL}

O seminário acontece em um lugar físico onde alunos e professores se encontram, sendo uma prática dinâmica que pode acontecer individualmente ou em um grupo de alunos, que realizam uma pesquisa sobre um determinado tema com o intuito de explorá-lo e posteriormente, expor à todos da turma.

O seminário virtual empregado na área da saúde acontece em um fórum e segue o mesmo raciocínio do tradicional. Professores/tutores realizam um trabalho de sensibilização para 
que haja comprometimento por parte dos alunos. O objetivo desse tipo de instrumento de avalição é apresentar o assunto através do uso de diferentes formas de contrução coletiva online (FERREIRA, 2014).

Os temas e a distribuição dos alunos nos grupos podem ser determinados pelo próprio professor ou de acordo com a vontade dos alunos, tudo relaciona-se a intensão pedagógica. $O$ tempo para que os seminários sejam desenvolvidos não pode ser inferior a um mês.

\section{CONSIDERAÇÕES FINAIS}

O desenvolvimento de diferentes tecnologias estabelece mudanças no homem e cria desafios, surgindo a necessidade de se adaptar as inovações decorrentes da Era Digital. Quando associada a educação, une os indivíduos aos estudos, com o intuito de maior qualificação e qualidade de vida.

Inúmeros trabalhos demonstram a importância da educação a distância em nosso país, já que muitos alunos não teriam a oportunidade de realizar um curso se esse tipo de educação não existisse, onde a avaliação da aprendizagem é um modelo moderno que necessita disvincular-se da avaliação tradicional.

Mas fazer com que a educação a distância seja um instrumento de avaliação com o intuito de impulsionar o conhecimento, possibilitando a aprendizagem, ainda é algo a ser construído, onde a reflexão e a ação devem permanecer para que essa prática seja estabelecida.

O uso do portfólio como instrumento de avaliação estabelece relações na prática pedagógica, onde ocorre o estreitamento dos laços entre o aluno e o docente, culminando em uma aprendizagem significativa e real, aproximando-os. Através de sua aplicação é possível ampliar os instrumentos de avaliação, permitindo avaliar o aluno em diferentes aspectos.

Outra ferramenta de avaliação é o fórum de discussão, que possibilita avaliar a aprendizagem de todos os alunos, promovendo diferentes reflexões, diálogos e informações, onde todas as etapas desse processo são planejadas. Sendo assim, um ambiente que promove a avaliação crítica, diálogos, discussões, além da autoavaliação.

Mapas conceituais são úteis no auxílio da determinação do conhecimento de cada aluno, ajudando na investigação de sua estrutura cognitiva durante a instrução, servindo como feedback na hora de avaliá-lo. A realização do seminário virtual é de extrema importância e deve ser acompanhado e orientado pelo docente a todo momento. Se esse tipo de prática for entendida como um jogo, é importante que suas regras sejam claras e que os jogadores sejam bem instruídos e preparados.

Desta forma, o uso dos diferentes instrumentos de avaliação contribuem no processo de ensino e aprendizagem, promovendo interação e maior conhecimento entre os indivíduos, sendo a EAD uma tendência na área da saúde, pois fortalece e transforma a cada dia as práticas dos profissionais dessa área.

\section{REFERÊNCIAS}

BUCHWEITZ, B. O uso de mapas conceituais na análise do currículo. Educação e Seleção, n. 10, p. 3-16, 2013.

DARSIE, M. M. P. Avaliação e aprendizagem. Cadernos de Pesquisa, São Paulo, n. 99, p. 47-59, nov. 2013.

DE MORAIS BICALHO, R. N.; DE OLIVEIRA, M. C. S. L. O processo dialógico de construção do conhecimento em fóruns de discussão. Distance Education, v. 16, n. 41, p. 469-83, abr./ jun. 2012. 
FRANÇA, Rômulo Martins et al. Vantagens da utlização do fórum no ambiente virtual de aprendizagem. 2014.

LORENZETTI, J et al. Tecnologia, inovação tecnológica e saúde: uma reflexão necessária. Texto and Contexto Enfermagem, Florianópolis, v. 21, n. 2, p. 432,abr/ jun. 2012.

MOREIRA, M. A. O mapa conceitual como instrumento de avaliação da aprendizagem. Educação e Seleção, n. 10, p. 17-34, 2013.

PILETTI, C. Didática geral. 4. Ed. São Paulo: Ática, 1987.

PINTO, A. M. As novas tecnologias e a educação. Revista Portal Anpedsul, v. 5, p. 20-30. 2012.

RODRIGUES, N. V. M.; BORGES, F. T. Avaliação da aprendizagem em educação a distância através do fórum (interface educacional). Ideias e Inovação, Aracaju, v. 1, n. 2, p. 25-34, mai. 2013.

VILLAS BOAS, B. M. F. O portfólio no curso de Pedagogia: ampliando o diálogo entre professor e aluno. Educ. Soc., Campinas, v.26, n.90, p.291-306, jan./abril. 2005.

VILLAS B. M.F.V. Portfólio, avaliação e trabalho pedagógico. 5 Ed. Campinas: Papyrus, 2004. Disponível em: < https://books.google.com.br/books?hl=ptBR\&Ir=\&id=EZVGYOT_mKOC\&oi=fnd\&pg=PA9\&dq=Portf\%C3\%B3lio,+avalia\%C3\%A7\%C3\%A3o+e+t rabalho+pedag\%C3\%B3gico\&ots=6ge8_9-

zpu\&sig=88iajod4HAq0lqF8v5oPtbSKCsM\#v=onepage\&q=Portf\%C3\%B3lio\%2C\%20avalia\%C3\%A7\% C3\%A30\%20e\%20trabalho\%20pedag\%C3\%B3gico\&f=false>. Acesso em: 04 jan. 2016. 